\title{
Optimalisasi Penggunaan Alat Berat pada Pekerjaan Galian Jalan Lintas Rel Kereta Api Rantau Prapat - Kotapinang - Sumatera Utara
}

\author{
Alimunawar ${ }^{1}$,Fadrizal Lubis ${ }^{2}$, Winayati ${ }^{3}$ \\ Program Studi Teknik Sipil, Fakultas Teknik, Universitas Lancang Kuning \\ Jl. Yos Sudarso km. 8 Rumbai, Pekanbaru, Telp. (0761) 52324 \\ Email:ali_mnwr@yahoo.com, , fadrizal@unilak.ac.id,winayati@unilak.ac.id
}

\begin{abstract}
ABSTRAK
Pelaksanaan proyek pembangunan jalur kereta api Rantau Prapat - Kota Pinang PT. ADHI KARYA Pekerjaan penggalian membutuhkan beberapa macam Alat berat yang bekerja saling berhubungan satu dengan yang lainnya. Komposisi alat berat yang digunakan oleh kontraktor pelaksana untuk pekerjaan penggalian menggunakan pemakaian alat berat dengan komposisi 2 unit excavator, 5 unit dump truck, dan 1 unit bulldozer. Dengan waktu pelaksanaan selama 833 hari. Dari tanggal 20 september 2017 sampai dengan 30 desember 2019. Rumusan masalah penelitian ini adalah bagaimana komposisi alat berat yang optimal yaitu efektif dan efisien dari segi waktu dan biaya untuk pekerjaan galian tanah pada proyek jalur rel kereta api antar kota yang menghubungkan Rantau Prapat dan Kota Pinang Penelitian dilakukan menggunakan metode deskriptif. Yang mana. Perhitungan dilakukan sesuai dengan kapasitas dan kemampuan alat berat yang dipergunakan pada proyek Pekerjaan penggalian dengan volume $317.622 \mathrm{~m}^{3}$. Komposisi alat berat yang optimal (yang efektif dan efisien dari segi waktu dan biaya) adalah pada alternatif III dengan komposisi 2 unit excavator 19 unit dump truck dan 1 unit bulldozer. Waktu yang dibutuhkan pada komposisi ini adalah 84 hari. Selisih 194 hari lebih cepat dari komposisi yang ditetapkan oleh kontraktor pelaksana dengan selisih biaya Rp 1.788.981208,96. Biaya yang dikeluarkan oleh alternatif III paling rendah dan paling cepat dari alternatif lainnya sehingga alternatif III layak untuk direalisasikan.
\end{abstract}

Kata kunci : Alatberat, Efesiensi alat

\begin{abstract}
Implementation of Rantau Prapat - Kota Pinang railway development project PT. ADHI KARYA Excavation work requires several kinds of heavy equipment that work interconnected with each other. The composition of heavy equipment used by the contractor for excavation works using the use of heavy equipment with the composition of 2 units of excavators, 5 units of dump trucks, and 1 unit of bulldozers. With an implementation time of 833 days. From September 20, 2017 to December 30, 2019. The formulation of this research problem is how the optimal composition of the machine is effective and efficient in terms of time and cost for soil excavation work on inter-city railway project connecting Rantau Prapat and Kota Pinang The research was conducted using descriptive method. Which one. The calculation is performed in accordance with the capacity and the capacity of the equipment used in the excavation project with volume $317,622 \mathrm{~m} 3$. The optimal machine composition (which is effective and efficient in terms of time and cost) is in alternative III with the composition of 2 units of excavators 19 units of dump trucks and 1 unit of bulldozers. The time required for this composition is 84 days. The difference is 194 days faster than the composition set by the implementing contractor with a difference of $R p$ 1,788,981,208,96. The costs incurred by the alternative III are the lowest and the fastest of the other alternatives so that alternative III is feasible to be realized.
\end{abstract}

Keywords: Device Weight, Efficiency tool

\section{PENDAhuluan}

Kereta api adalah sarana transportasi berupa kendaraan dengan tenaga gerak, baik berjalan sendiri maupun dirangkaikan dengan kendaraan lainnya. Kereta api merupakan alat tranportasi massal yang umumnya terdiri dari lokomotif (kendaraan dengan tenaga gerak yang berjalan sendiri) dan rangkaian kereta atau gerbong (dirangkaikan dengan kendaraan lainnya). Karena sifatnya sebagai angkutan massal, beberapa negara berusaha memanfaatkan secara maksimal sebagai alat transportasi utama angkutan 
darat baik didalam kota, antar kota, maupun antar negara. Dengan tugas pokok dan fungsi memobilisasi arus penumpang dan barang diatas jalur rel kereta api, sehingga kereta api ikut berperan menunjang pertumbuhan ekonomi nasional. Dengan demikian ketersediaan jalan kereta api yang baik, aman dan nyaman untuk dilalui merupakan salah satu syarat untuk memajukan suatu daerah.

Dalam pelaksanaan proyek pembangunan jalan kereta api Rantau Prapat Kota Pinang, PT. ADHI KARYA mendapatkan kontrak dipaket 5 dari KM 17+000 sampai dengan KM 20+500 (3.500 m) dengan waktu pelaksanaan dari tanggal 20 September 2017 sampai dengan 31 Desember 2019(833 hari kalender). Dikarenakan masalah perubahan design (asjalur dan elevasi permukaan rel) berdampak pada keterlambatan mulainya pekerjaan jalur dan bangunan yang rencana mulai dikerjakan pada tanggal 13 Nopember 2017 mundur waktu pelaksanaan yang direncanakan sekitar tanggal 20 maret 2018 pekerjaan penggalian dan timbunan baru bisa dilakukan. Kontraktor pelaksana PT. ADHI KARYA menggunakan pemakaian alat berat dengan komposisi 2 unit excavator, 5 unit dumptruck, dan 1 unit bulldozer. Dengan waktu pelaksanaan pekerjaan tanah dari tanggal 13 Nopember 2017 sampai dengan 27 Oktober 2019. Maka dari analisa existing tersebut, dapat diperhitungan kembali terhadap optimalisasi penggunaan alat berat pada pekerjaan galian jalan rel kereta api yang menghubungkan Rantau Prapat dan Kota Pinang. Karena mundurnya waktu pelaksanaan kerja, berdampak pada sisa waktu yang direncanakan kontraktor.

\section{METODE PENELITIAN}

Data-data dikumpulkan dengan beberapa cara, mulai dari pengumpulan data di lapangan, mempelajari masalah yang diangkat, dan mencari informasi tambahan dengan mengajukan berbagai pertanyaan kepada nara sumber. Cara mengumpulkan data-data penelitian ini adalah :

1. Observasi langsung dilakukan dengan cara mendatangi lokasi proyek dan selanjutnya mencatat hasil pengamatan secara umum tentang situasi dan kondisi pelaksanaan proyek terutama kegiatan alat berat yang mengerjakan pekerjaan penimbunan pada bahu jalan dimaksud.

2. Studi literaturecara ini dilakukan dengan mempelajari berkas-berkas perencanaan yang ada pada Dinas Pekerjaan Umum dan selanjutnya mencocokkannya dengan hasil observasi langsung. Selain itujuga dilakukan survey terhadapharga jual atau sewa alat di daerah.

3. Wawancara dilakukan dengan pihak-pihak yang terlibat dengan pelaksanaan proyek, termasuk tempat penyewaan alat berat.

Data-data yang dikumpulkan selanjutnya diolah guna menyelesaikan penelitian ini. Data-data tersebut dapat dikelompokkan menjadi dua kelompok yang terdiri dari :

1. Data Primermerupakan data-data yang diperoleh dari sumber pertama berupa catatan hasil observasi. Data-data primer yang dikumpulkan pada penelitian ini terdiri dari :
a. Catatan hasil observasi
b. Catatan hasil wawancara dengan pihak terkait.

2. Data Sekundermerupakan data olahan atau berasal dari data primer yang telah diolah lebih lanjut dan disajikan oleh pihak pengumpul data primer atau oleh pihak lain. Biasanya data sekunder ditampilkan dalam bentuk tabel-tabel atau diagram-diagram. Data tersebut berupa :
a. Data perencanaan proyek
b. Catatan observasi c. Daftar harga, indeks, kapasitas dan sewa
peralatan.
d. RAB

\subsubsection{Data penelitian}

Kondisi tanah yang terdapat pada lokasi proyek adalah tanah biasa.Kontur tanah yang berbukit-bukit memerlukan usaha perataan. Pekerjaan yang akan dilakukan meliputi penggalian bukit di quarry dan penimbunan bagian yang rendah atau rawa. Pekerjaan galian tanah di lokasi proyek adalah sebagai berikut:

1. Pekerjaan galian tanah yaitu sebesar $317.622 \mathrm{~m}^{3}$

2. Jarak tempat pembuanganhasil tanah galian adalahsekitar $5 \mathrm{~km}$ dari lokasipekerjaan galian tanah.

3. Komposisi alat berat yang direncanakan kontraktor adalah ;2 unit excavator, 1unit bulldozer, 5 unit dump truck.

4. Data existing alat berat yang digunakan pada proyek penggalian tanah adalah sebagai berikut:

a) Excavator; jumlahexcavatoryang digunakan diperkirakandua unit, untuk menggali tanah. Kondisi excavator yang digunakan $90 \%$ yang dengan faktor efisiensi dinyatakan dalam kondisi 'baik'. Data-data teknis alat excavator sebagai berikut :

1) Merek Komatsu tipe PC 200

2) Daya $125 \mathrm{HP}$

3) Kapasitas bucket $0,50 \quad{ }^{7} \mathrm{~m}^{3}$

4) Sudut ayun (swing) $45^{\circ}-90^{\circ}$

b) Bulldozer ; jumlahbulldozeryang digunakan diperkirakansatu unit. Sesuai dengan fungsinya, bulldozer dipakai untuk meratakan tanah yang telah digali dilokasi buangan. Data teknis bulldozer yang digunakan adalah :

1) Merek 'Caterpilar' tipe $\mathrm{D} 7 \mathrm{H}-8$

2) Daya $155 \mathrm{HP}$

3) Lebar blade $=\quad 3,980 \mathrm{~m}$ (tabel 2.10)

4) Tinggi blade $=\quad 1,550 \mathrm{~m}$ (tabel 2.10)

5) Kecepatan maju : 

a) Gear $1=$
$0-3,9 \mathrm{~km} / \mathrm{jam}$
b) Gear 2 =
$0-6,8 \mathrm{~km} / \mathrm{jam}$
c) Gear $3=$
$0-10,9 \mathrm{~km} / \mathrm{jam}$

6) Kecepatan mundur :
a) Gear $1=$
$0-5,0 \mathrm{~km} / \mathrm{jam}$
b) Gear $2=$
$0-8,6 \mathrm{~km} / \mathrm{jam}$
c) Gear $3=$
$0-13,7 \mathrm{~km} / \mathrm{jam}$

c) Dump Truck; jumlahdump truckyang digunakan disesuaikan dengan kebutuhan. Tanah yang telah digali oleh excavator selanjutnya diangkut oleh truk ke tempat pembuangan. Dump truck yang digunakan memiliki data teknis sebagai berikut:
1) Merek 'Nissan Diesel' tipe CWB 450 HD
2) Kapasitas bak $14 \mathrm{~m}^{3}$
3) Daya $190 \mathrm{HP}$

\section{Bagan Alir Penelitian}

Bagan alir penelitian mengenai optimalisasi penggunaan alat berat untuk pekerjaan galian jalan rel kereta api antar kota yang menghubungkan RantauPrapat dan Kota Pinang dapat dilihat pada gambar 1.

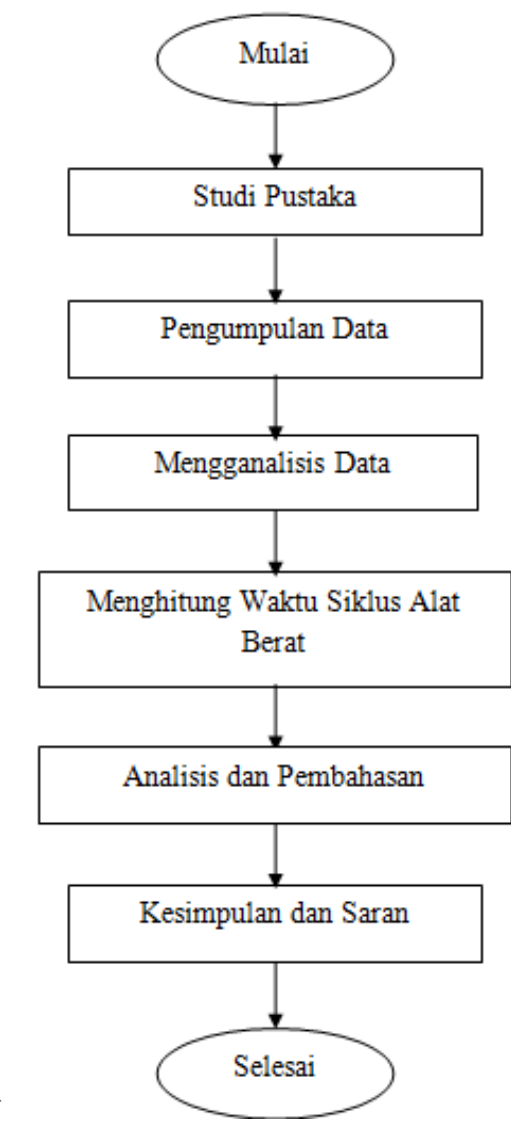

Gambar 1. Diagram alir penelitian

3. HASIL DAN PEMBAHASAN

Analisis data penelitian
Jalan lintas kereta api antar kota yang menghubungkan Rantau Prapat dan Kota Pinang sepanjang $3500 \mathrm{~m}$. Kondisi tanah yang terdapat pada lokasi proyek tersebut adalah tanah biasa. Kontur tanah yang berbukit-bukit memerlukan usaha perataan. Pekerjaan yang akan dilakukan meliputi penggalian bukit dan pembuangan tanah hasil galian ke tempat buangan. Pekerjaan galian di lokasi proyek pembuatan jalan rel kereta api adalah sebagai berikut

$$
\begin{aligned}
\text { 1. Sta } 17+000-17+500 & =18.955,95 \mathrm{~m}^{3} \\
\text { 2. Sta } 17+500-18+000 & =28.865,91 \mathrm{~m}^{3} \\
\text { 3. Sta } 18+000-18+500 & =18.375,13 \mathrm{~m}^{3} \\
\text { 4. Sta } 18+500-19+000 & =50.470,94 \mathrm{~m}^{3} \\
\text { 5. Sta } 19+000-19+500 & =38.779,49 \mathrm{~m}^{3} \\
\text { 6. Sta } 19+500-20+000 & =109.700,40 \mathrm{~m}^{3} \\
\text { 7. Sta } 20+000-20+500 & =52.474,04 \mathrm{~m}^{3} \\
\text { Total } & =317.622,10 \mathrm{~m}^{3}
\end{aligned}
$$

Produktivitas masing-masing peralatan berat yang digunakan disesuaikan dengan jenis, model, dan kapasitasnya. Produktivitas tersebut diperhitungkan untuk mengukur waktu yang dibutuhkan guna menyelesaikan pekerjaan sesuai dengan volume pekerjaan. Produktivitas masing-masing alat berat yang digunakan pada proyekpembangunan jalan rel kereta api antara Rantau Prapat - Kota Pinang adalah :

1. Excavator backhoe

Excavator melakukan penggalian di lokasi proyek. Kontur tanah yang bergelombang atau berbukit memerlukan penggaliansesuai dengan elevasi yang direncanakan. Total panjang jalur galian tanah adalah $3.500 \mathrm{~m}$ dengan volume sebanyak $317.622 \mathrm{~m}^{3}$. Jumlah waktu yang dibutuhkan untuk menyelesaikan pekerjaan penggalian tersebut diperhitungkan sebagai berikut :

a. Kapasitas aktual excavator backhoe

$$
\begin{aligned}
\mathrm{F} & =0,83 \\
\mathrm{q}_{1} & =1,17 \mathrm{~m}^{3} \\
\mathrm{k} & =1,15 \\
\mathrm{q} & =\mathrm{q}_{1} \times \mathrm{k} \\
& =1,17 \times 1,15 \\
& =1,3455 \mathrm{~m}^{3}
\end{aligned}
$$

b. Waktu siklus excavator backhoe

$$
\begin{aligned}
\mathrm{t}_{\mathrm{m}} & =14,5 \mathrm{dt} \\
\mathrm{C}_{\mathrm{f}} & =1 \\
\mathrm{C}_{\mathrm{m}} & =\mathrm{t}_{\mathrm{m}} \times \mathrm{C}_{\mathrm{f}} \\
& =14,5 \times 1 \\
& =14,5 \text { detik }
\end{aligned}
$$

c. Produksi kerja aktual 


$$
\begin{aligned}
\mathrm{Q} & =\frac{\mathrm{q} \times 3600 \times \mathrm{F}}{\mathrm{C}_{\mathrm{m}}} \\
& =\frac{1,3455 \times 3600 \times 0,83}{14,5} \\
& =277,266 \mathrm{~m}^{3} / \mathrm{jam}
\end{aligned}
$$

d. Waktu yang dibutuhkan

$$
\begin{aligned}
\mathrm{T} & =\frac{\text { Volume Tanah }}{\mathrm{Q}} \\
& =\frac{317.622 \mathrm{~m}^{3}}{277,265 \mathrm{~m}^{3} / \mathrm{jam}} \\
& =1.145,55 \mathrm{jam}: 8 \text { jam/hari } \\
& =143,19 \text { hari } \\
& \approx 144 \text { hari }
\end{aligned}
$$

Berdasarkan hasil perhitungan yang disesuaikan dengan model dan kapasitas 1 unit excavatorbackhoe yang digunakan, untuk menggali tanah sebanyak $317.622 \mathrm{~m}^{3}$ dibutuhkan waktu 144 hari kerja untuk satu unit excavator backhoe.

\section{Dump truck}

Setelah tanah digali, tanah tersebut dan dimasukkan ke dalam bak dump truck.Dump truckdigunakan untuk mengangkut tanah yang digali darilokasi jalan rencana. Tanah hasil galian diangkut kelokasi buangan sejauh $5 \mathrm{Km}$ sebanyak $317.622 \mathrm{~m}^{3}$. Perhitungan yang dilakukan untuk mengetahui total waktu yang dibutuhkan dump truck untuk mengangkut tanah bolakbalik adalah sebagai berikut :
1. Data yang diketahui :
a. Volume $=317.622 \mathrm{~m}^{3}$
b. $\mathrm{q}_{1} \quad=14 \mathrm{~m}^{3}$
c. $\mathrm{k} \quad=1,15$
d. $\mathrm{F} \quad=0,83$
e. $Q_{p} \quad=277,266 \mathrm{~m}^{3} / \mathrm{jam}$
f. $\mathrm{t}_{3} \quad=0,7$ menit
g. $\mathrm{t}_{4} \quad=1,1$ menit
h. D $=5 \mathrm{~km}$
i. $\mathrm{V}_{1} \quad=25 \mathrm{~km} / \mathrm{jam}$
j. $\mathrm{V}_{2} \quad=\quad 30 \mathrm{~km} / \mathrm{jam}$

2. Kapasitas aktual bak (q)

$$
\begin{aligned}
\mathrm{Q} & =\mathrm{q}_{1} \times \mathrm{k} \\
& =14 \mathrm{~m}^{3} \times 1,15 \\
& =16,1 \mathrm{~m}^{3}
\end{aligned}
$$

3. Waktu muat $\left(\mathrm{t}_{\mathrm{m}}\right)$

$$
\mathrm{tm}=\frac{\mathrm{q} 1}{\mathrm{Qp}} \times 60
$$

$$
\begin{aligned}
\mathrm{tm} & =\frac{14 \mathrm{~m} 3}{277,266 \mathrm{~m} 3 / \mathrm{jam}} \times 60 \text { menit/jam } \\
& =3,03 \text { menit }
\end{aligned}
$$

4. Waktu angkut $\left(\mathrm{t}_{1}\right)$

$$
\begin{aligned}
\mathrm{t} 1 & =\frac{\mathrm{D}}{\mathrm{V} 1} \times 60 \\
\mathrm{t} 1 & =\frac{5 \mathrm{~km}}{25 \mathrm{~km} / \mathrm{jam}} \times 60 \mathrm{menit} / \mathrm{jam} \\
& =12 \text { menit }
\end{aligned}
$$

5. Waktu kembali $\left(\mathrm{t}_{2}\right)$

$$
\begin{aligned}
\mathrm{t} 2 & =\frac{\mathrm{D}}{\mathrm{V} 1} \times 60 \\
\mathrm{t} 2 & =\frac{5 \mathrm{~km}}{30 \mathrm{~km} / \mathrm{jam}} \times 60 \text { menit } / \mathrm{jam} \\
& =10 \text { menit }
\end{aligned}
$$

6. Waktu siklus $\left(\mathrm{C}_{\mathrm{m}}\right)$

$$
\begin{aligned}
\mathrm{C}_{\mathrm{m}} & =\mathrm{t}_{\mathrm{m}}+\mathrm{t}_{1}+\mathrm{t}_{2}+\mathrm{t}_{3}+\mathrm{t}_{4} \\
& =(3,03+12+10+0,7+1,1) \\
& =26,83 \text { menit }
\end{aligned}
$$

7. Produksi kerja aktual (Q)

$$
\begin{aligned}
\mathrm{Q} & =\frac{\mathrm{q} \times 60 \times \mathrm{F}}{\mathrm{C}_{\mathrm{m}}} \\
& =\frac{16,1 \mathrm{~m}^{3} \times 60 \text { menit/jam } \times 0,83}{26,83 \text { menit }} \\
& =29,88 \mathrm{~m}^{3} / \mathrm{jam}
\end{aligned}
$$

8. Jumlah dumptruck yang dibutuhkan

$$
\begin{aligned}
\text { Dump truck } & =\frac{\text { Produksi Kerja Aktual Excavator }}{\text { Produksi Kerja Aktual }} \\
\text { DumpTruck } & =\frac{277,266 \mathrm{~m}^{3} / \mathrm{jam}}{29,88 \mathrm{~m}^{3} / \mathrm{jam}} \\
& =9,7 \mathrm{unit} \\
& \approx 10 \text { unit }
\end{aligned}
$$

Jumlah dump truck yang sesuai dengan kapasitas excavator untuk memindahkan atau mengangkut seluruh tanah hasil galian sebanyak $317.622 \mathrm{~m}^{3}$ adalah 10 unit.

\section{Excavator backhoe}

Tanah yang dibuang memerlukan tindakan perataan yang dilakukan oleh bulldozer. Perhitungan produktivitas bulldozer adalah :

a. Diketahui :

$$
\begin{array}{ll}
\text { Lebar blade }(\mathrm{L}) & =3,980 \mathrm{~m} \\
\text { Tinggi blade }(\mathrm{H}) & =1,550 \mathrm{~m} \\
\mathrm{~F} & =0,75 \\
\text { Faktor blade }(\mathrm{a}) & =1 \\
\mathrm{D} & =50 \mathrm{~m} \\
\mathrm{~F}_{\mathrm{s}} & =6.8 \times 0,75
\end{array}
$$




$$
\begin{aligned}
& =5,1 \mathrm{~km} / \mathrm{jam} \\
\mathrm{R}_{\mathrm{s}} & =8,6 \times 0,75 \\
& =6,45 \mathrm{~km} / \mathrm{jam}
\end{aligned}
$$

Lepas $=1,25$

b. Kapasitas Aktual $\mathrm{q}$

$$
\begin{aligned}
& =\mathrm{a} \times \mathrm{L} \times \mathrm{H}^{2} \\
& =1 \times 3,980 \times(1,550 \\
& \mathrm{m})^{2} \\
& =9,56 \mathrm{~m}^{3}
\end{aligned}
$$

c. Waktu Siklus

$$
\begin{aligned}
\mathrm{C}_{\mathrm{m}} & =\frac{\mathrm{D}}{\mathrm{F}_{\mathrm{s}}}+\frac{\mathrm{D}}{\mathrm{R}_{\mathrm{s}}}+\mathrm{Z} \\
& =\frac{50 \mathrm{~m}}{85 \mathrm{~m}}+\frac{50 \mathrm{~m}}{107,5 \mathrm{~m}}+0,075 \mathrm{~m} \\
& =1,3 \text { menit }
\end{aligned}
$$

d. Produktivitas bulldozer untuk tanah lepas :

$$
\begin{aligned}
Q & =\mathrm{q} \times 60 \frac{60 \mathrm{~F} \times \mathrm{C}_{\mathrm{f}}}{\mathrm{C}_{\mathrm{m}}} \\
& =9,56 \mathrm{~m}^{3} \times \frac{60 \mathrm{menit} / \mathrm{jam} \times 0,75 \times 1,25}{1,13 \mathrm{menit}} \\
& =475,8 \mathrm{~m}^{3} / \mathrm{jam} \\
& =476 \mathrm{~m}^{3} / \mathrm{jam}
\end{aligned}
$$

e. Produktivitas bulldozer untuk pekerjaan tanah di lokasi :

$\mathrm{T}=$ Volume Tanah

Q

$$
\begin{aligned}
& =\frac{317.622 \mathrm{~m}^{3}}{476 \mathrm{~m}^{3} / \mathrm{jam}} \\
& =667,4 \text { jam }: 8 \mathrm{jam} \\
& =83,4 \text { hari } \\
& =84 \text { hari }
\end{aligned}
$$

Waktu yang diperlukan bagi bulldozer untuk meratakan tanah buangan perunit selama 84 hari kerja, dengan jarak $5 \mathrm{~km}$ dari lokasi penggalian proyek ke lokasi tempat buangan tanah hasil galian tersebut dengan volume $317.622 \mathrm{~m}^{3}$.

Tabel 4.2 Alternatif komposisi penggunaan alat berat

\begin{tabular}{|c|l|c|c|c|c|c|c|}
\hline \multirow{2}{*}{ No } & \multirow{2}{*}{ Nama Alat } & \multicolumn{2}{|c|}{$\begin{array}{c}\text { Alternatif-I } \\
\text { Kondisi Existing }\end{array}$} & \multicolumn{2}{|c|}{ Alternatif-II } & \multicolumn{2}{|c|}{ Alternatif-III } \\
\cline { 3 - 8 } & $\begin{array}{c}\text { Jumlah } \\
\text { alat berat } \\
\text { (unit) }\end{array}$ & $\begin{array}{c}\text { Waktu } \\
\text { (hari) }\end{array}$ & $\begin{array}{c}\text { Jumlah } \\
\text { alat berat } \\
\text { (unit) }\end{array}$ & $\begin{array}{c}\text { Waktu } \\
\text { (hari) }\end{array}$ & $\begin{array}{c}\text { Jumlah } \\
\text { alat berat } \\
\text { (unit) }\end{array}$ & $\begin{array}{c}\text { Waktu } \\
\text { (hari) }\end{array}$ \\
\hline 1 & $\begin{array}{l}\text { Excavator Backhoe 125 } \\
\text { HP }\end{array}$ & 2 & 266 & 1 & 144 & 2 & 72 \\
\hline 2 & Dump Truck $190 \mathrm{HP}$ & 5 & 266 & 10 & 144 & 19 & 72 \\
\hline 3 & Bulldozer $155 \mathrm{HP}$ & 1 & 266 & 1 & 144 & 1 & 84 \\
\hline
\end{tabular}

(Sumber : Analisis Data, 2018)

Jika dibandingkan dengan komposisi optimal menurut perhitungan yang dilakukan jumlah dump truck yang diperhitungkan lebih dari 3 kali jumlah yang ditetapkan oleh kontraktor. Dengan demikian perlu diperhitungkan kembali komposisi yang digunakan oleh kontraktor baik dari segi waktu yang dihabiskan maupun biaya yang akan digunakan.

Penilaian optimal atau tidaknya komposisi alat berat yang disusun untuk mengerjakan suatu pekerjaan tergantung dari efisiensi alat-alat yang digunakan.Selain itu faktor biaya yang dikeluarkan dan waktu yang dihabiskan untuk menyelesaikan seluruh pekerjaan pun ikut menjadi pertimbangan dalam memilih komposisi mana yang lebih baik.Berikut ini diperhitungkan kembali tiga alternatif komposisi alat berat untuk pekerjaan galian tanah pada pekerjaan jalan kereta api Rantau Prapat sampai dengan Kota Pinang.Perhitungan efisiensi, biaya dan waktu menjadi patokan bagi pemilihan alternatif mana yang paling optimal diantara 3 macam alternatif tersebut. Perhitungan komposisi tersebut adalah:

1. Alternatif I (Kondisi Existing);

a. Komposisi 2 unit excavator- 5unit dump truck - 1 unit bulldozer.

b. Waktu yang diperlukan 266 hari

c. Waktu kerja 1 hari adalah 8 jam.

d. Biaya alat perunit perjam ;excavator $\mathrm{Rp}$ 620.518,57; dump truck $\mathrm{Rp}$ 451.014,58; bulldozer $\operatorname{Rp} 783.527,85$

e. Perhitungan biaya hingga selesai pekerjaan galian tanah :

(jumlah alat berat $\mathrm{x}$ hari kerja $\mathrm{x} 8$ jam/hari $\mathrm{x}$ biaya perunit perjam)
2excavator $=\mathrm{Rp} 2.640 .927 .033,92$
5dump truck $=\mathrm{Rp} 4.798 .795 .131,20$
1bulldozer $=\mathrm{Rp}$ 1.667.347.264,80
Total biaya alat berat

Rp9.107.069.429,92

2. Alternatif II ;

a. Komposisi 1 unit excavator - 10 unit dump truck - 1 unit bulldozer.

b. Waktu yang diperlukan 144 hari.

c. Waktu kerja 1 hari adalah 8 jam.

d. Biaya alat perunit perjam ;excavator $\mathrm{Rp}$ 620.518,57 ; dump truck $\mathrm{Rp} 451.014,58$; bulldozer $\operatorname{Rp} 783.527,85$ 
e. Perhitungan biaya hingga selesai pekerjaan galian tanah :

(jumlah alat berat $\mathrm{x}$ hari kerja $\mathrm{x} 8$ jam/hari $\mathrm{x}$ biaya perunit perjam)

$$
\begin{array}{ll}
\text { 1excavator } & =\operatorname{Rp} 714.837 .392,64 \\
\text { 10dump truck } & =\operatorname{Rp} 5.195 .687 .961,60 \\
1 \text { bulldozer } & =\operatorname{Rp} 902.624 .083,20
\end{array}
$$

Total biaya alat berat

Rp 6.813.149.437,44

3. Alternatif III ;

a. Komposisi 2 unit excavator - 19 unit dump truck - 1 unit bulldozer.

b. Waktu yang diperlukan 72 hari untuk excavator dan 19dump truck sementara1bulldozer hanya membutuhkan 84 hari kerja.

c. Waktu kerja 1 hari adalah 8 jam.

d. Biaya alat perunit perjam ;excavator $\mathrm{Rp}$ 620.518,57 ; dump truck Rp 451.014,58; bulldozer $\mathrm{Rp} 783.527,85$

e. Perhitungan biaya hingga selesai pekerjaan galian tanah :

(jumlah alat berat $\mathrm{x}$ hari kerja $\mathrm{x} 8$ jam/hari $\mathrm{x}$ biaya perunit perjam)

$$
\begin{aligned}
& 2 \text { excavator }=\operatorname{Rp} 714.837 .392,64 \\
& 19 \text { dump truck }=\operatorname{Rp} \quad 4.935 .903 .563,52 \\
& 1 \text { bulldozer }=\operatorname{Rp} \quad 526.530 .715,20 \\
& \text { Total biaya alat berat }
\end{aligned}
$$

$$
\text { Rp6.177.271.671,36 }
$$

Dari hasil perhitungan biaya yang dikeluarkan untuk beberapa komposisi alat berat, Pada alternatif I merupakan komposisi alat berat yang direncanakan oleh kontraktor dengan biaya yang paling tinggi diantara duaalternatif. Ini dikarenakan pemakaian excavator backhoedan bulldozeryang tidak efektif. Pada alternatif II didapatkan dari hasil perhitungan analisa dengan waktu lebih cepat 122 hari dan selisih biaya sebesar Rp 2.293.919.992,48. Pada alternatif III yaitu komposisi 2 unit excavator backhoe, 19 unit

\begin{tabular}{|c|c|c|c|c|c|c|}
\hline \multicolumn{4}{|c|}{ ALTERNATIF III } & \multicolumn{3}{|c|}{ PEKERJAAN GALIAN } \\
\hline NO & Nama Alat & \begin{tabular}{|c|}
$\begin{array}{c}\text { Biaya Operasional } \\
(\mathrm{Rp} / \mathrm{jam}\end{array}$ \\
\end{tabular} & $\begin{array}{c}\text { Jumlah } \\
\text { unit }\end{array}$ & $\begin{array}{c}\text { Waktu Kerja } \\
\text { ( hari ) }\end{array}$ & Jam kerja & $\begin{array}{c}\text { Jumlah Biaya } \\
(\mathrm{Rp})\end{array}$ \\
\hline 1 & Excavator & $620,518.57$ & 2 & 72.00 & 8 & $714.837,392.64$ \\
\hline 2 & Dump trcuk & $451,014.58$ & 19 & 72.00 & 8 & $4,935,903,563.52$ \\
\hline 3 & Bulldozer & $783,527.85$ & 1 & 84.00 & 8 & $526,530,715.20$ \\
\hline & & & & & & \\
\hline & $\begin{array}{l}\text { TOTAL BIAYA } \\
\end{array}$ & ERJAAN GALIAN ALT & ERNATIF & III & & $6,177,271,671.36$ \\
\hline
\end{tabular}
dump truck dan 1 unit bulldozer total biaya yang dibutuhkan sebesar Rp 6.177.271.671,36 dan selisih biaya dengan alternatif I sebesar Rp 2.929.797.758,56 serta waktu yang lebih cepat 194 hari

Tabel 4.3 : Rekapitulasi Hasil Perhitungan Alat Berat

\begin{tabular}{|r|c|c|c|c|c|c|}
\hline \multicolumn{3}{|c|}{ ALTERNATIF I } & \multicolumn{3}{c|}{ PEKERJAAN GALIAN } \\
\hline \hline NO & Nama Alat & $\begin{array}{c}\text { Biaya Operasional } \\
\text { (Rp / jam }\end{array}$ & $\begin{array}{c}\text { Jumlah } \\
\text { unit }\end{array}$ & $\begin{array}{c}\text { Waktu Kerja } \\
\text { ( hari })\end{array}$ & Jam kerja & $\begin{array}{c}\text { Jumlah Biaya } \\
\text { ( Rp })\end{array}$ \\
\hline & & & & & & \\
\hline 1 & Excavator & $620,518.57$ & 2 & 266.00 & 8 & $2,640,927,033.92$ \\
\hline 2 & Dump trcuk & $451,014.58$ & 5 & 266.00 & 8 & $4,798,795,131.20$ \\
\hline 3 & Bulldozer & $783,527.85$ & 1 & 266.00 & 8 & $1,667,347,264.80$ \\
\hline & & & & & \\
\hline \hline
\end{tabular}

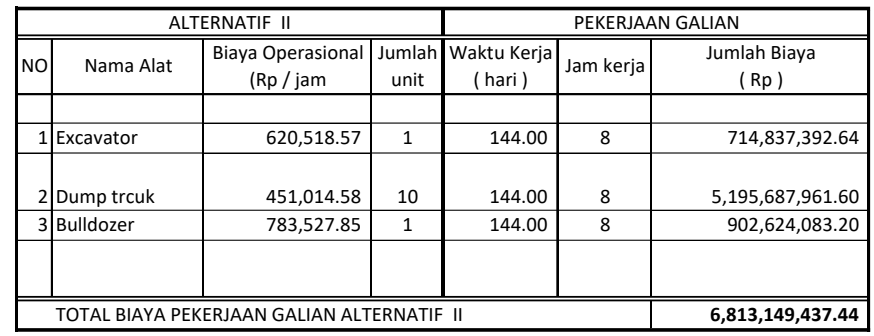
Selisih waktu dan biaya :

Alternatif II terhadap alternatif I $\quad$ - 122 Hari Rp -2.293.919.992,48 Alternatif III terhadap alternatif II $\quad-72$ Hari Rp $-635.877 .766,08$ Alternatif III terhadap alternatif I - $\quad 122$ Hari Rp -2.919.797.758,56

\section{Pembahasan}

Pada alternatif I dari komposisi alat berat 2 unit excavator backhoe, 5 unit dump truck dan 1 unit bulldozer membutuhkan biaya Rp 9.107.069.429,92, dengan membutuhkan waktu 266 hari kerja.Waktu kerja dalam satu hari diperhitungkan 8 jam. Jumlah dump truck yang kurang tanpa mempertimbangkan kapasitas kerja excavator backhoedan bulldozerpada alternatif I ini menyebabkan banyaknya waktu excavator backhoe dan bulldozer yang terbuang dikarenakan menunggu kedatangan dump truck dari lokasi buangan.Hal tersebut menunjukkan bahwa efisiensi excavator backhoe dan bulldozer tidak tercapai dan terbukti berdampak pada kenaikan biaya operasional alat tersebut. Kenaikannya mencapai $247 \%$ \% (( 2.640.927.033,92 + 1.667.347.264,80) $-(714.837 .392,64+526.530 .715,20)$ / $(714.837 .392,64+526.530 .715,20)) \times 100 \%$, sangat tidak ekonomis bila dilaksanakan dan waktu yang lebih lama.

Pada alternatif II, bulldozer yang digunakan sebanyak 1 unit, selama 144 hari karena mengikuti jam kerja alat 1 unit excavator backhoe dan 10 unit dump truck.Biaya yang dikeluarkan yaitu Rp 6.813.149.437,44.Namun perhitungan tidak selamanya dapat digunakan sebab ritme kerja alat, 1 unit bulldozer yang seharusnya dapat menyelesaikan perataan tanah selama 84 hari, dalam hal ini bulldozer harus mengikuti jam kerja alat yang lain yaitu 144 hari, dengan selisih waktu 60 hari dan biaya sebesar $(\mathrm{Rp} 902.624 .083,20$ - $\mathrm{Rp} 520.530 .715,20=\mathrm{Rp}$ 
376.093.368). Dengan demikian, alternatif IItidak ekonomis bila dilaksanakan.

Pada alternatif III, bulldozer yang digunakan sebanyak 1 unit selama 84 hari, 2 unit excavator backhoe dan 19 unit dump truck untuk lebih mempersingkat waktu pekerjaan alat tersebut menjadi 72 hari kerja.Biaya yang dikeluarkan yaitu Rp 6.177.271.671,36dengan selisih hari kerja 194 hari terhadap alternatif I. Lokasi pekerjaan dengan lebar 50 $\mathrm{m}$ dan panjang $3500 \mathrm{~m}$ serta jalan keluar masuk kelokasi yang cukup banyak, maka jumlah 19 unit dump truck tidak menimbulkan masalah mengenai lalu lintas dilokasi pekerjaan galian tanah tersebut.Pengaturan waktu kerja dapat dimulai bersamaan.Excavator backhoe melakukan penggalian tanah diikuti dengan dump truck untuk pengangkutannya dan bulldozer bisa meratakan tanah setelah tanah datang di lokasi buangan, dengan komposisi excavator backhoe 2 unit, bulldozer 1 unit dan dump truck 19 unit sangat ideal terhadap biaya dan waktu yang lebih cepat dari alternatif I. Maka alternatif III ini dapat dilaksanakan.

\section{KESIMPULAN DAN SARAN}

\section{Kesimpulan}

Berdasarkan hasil analisis dan perhitungan maka dapat ditarik kesimpulan sebagai berikut :

Dari hasil evaluasi yang dilakukan, ternyata komposisi alat berat yang direncanakan oleh kontraktor yang terdiri dari 2 unit excavator backhoe, 5 unit dump truckdan 1 unit bulldozermerupakan komposisi yang tidak optimal untuk pekerjaan galian tanah dipekerjaan jalan rel kereta api Rantau Prapat sampai dengan Kota Pinangkm 302dari kota Medan dengan total volume $317.622 \mathrm{~m}^{3}$.

Komposisi alat berat yang optimal (yang efektif dan efisien dari segi waktu dan biaya) adalah pada alternatif III dengan komposisi 2 unit excavator backhoe19 unit dump truck dan 1 unit bulldozer. Waktu yang dibutuhkan pada komposisi ini adalah 72 hari. Selisih 194 hari lebih cepat dari komposisi yang ditetapkan oleh kontraktor pelaksana dengan selisih biaya Rp 1.788.981.208,96. Dengan total volume tanah galian317.622 $\mathrm{m}^{3}$ adalah paling cepat waktu yang diselesaikan dari Alternatif lainnya yang mana alternatif I menyelesaikan pekerjaannya selama 266 hari dan Alternatif II selama 144 hari.

\section{Saran}

Perencanaan penggunaan alat berat yang baik, yang meliputi efisiensi kerja biaya dan waktu akan berdampak pada kelancaran pekerjaan di lapangan. Terkadang, pelaksanaan pekerjaan di lapangan berbeda dengan yang direncanakan. Hal tersebut masih dapat dimaklumi dan masih dapat ditolerir jika perbedaan tersebut tidak sampai menimbulkan sejumlah kerugian terutama bagi pihak pelaksana proyek. Banyak faktor yang menyebabkan terjadinya perbedaan tersebut seperti cuaca yang kurang mendukung, tingkat kesulitan kerja di lapangan, kurangnya kemahiran operator dan lain-lain. Sehubungan dengan alat berat yang akan dipergunakan pada pekerjaan galian tanah dan tanah tersebut mengandung akar akar sawit dan tidak sesuai dengan speksifikasi maka harus dibuang kelokasi pembuangan yang telah ditentukan, ada beberapa saran yang perlu dikemukakan, yaitu :

1. Bagi kontraktor yang hendak melaksanakan proyek, hendaknya memperkirakan siklus kerja alat yang efisien dan menghitung secara cermat biaya yang akan dikeluarkan agar biaya yang dikeluarkan dapat ditekan sekecil mungkin melalui efisiensi kerja alat yang digunakan. Selain itu, agar rencana siklus dan sirkulasi alat berat yang digunakan dapat berjalan sebagaimana yang direncanakan perlu dilakukan pengawasan secara baik.

2. Rambu-rambu pemberitahuan bahwa adanya pekerjaan dilokasi tersebut, dibuat dengan jarak yang cukup agar pengguna lalu lintas mengerti. Dalam hal ini perlu koordinasi dengan pihak PTPN 3.

3.

\section{DAFTAR PUSTAKA}

[1]Caterpillar.1995.Caterpillar Performance Handbook.Ed. 26. Illionis-USA:Caterpillar inc.

[2]Gushelmi. 2014. Evaluasi Penggunaan Alat Berat Pada Pekerjaan Penimbunan Perbaikan Jalan Minas - Kandis Km 39(Tugas Akhir). Pekanbaru : Program Study Teknik Sipil,Universitas Lancang Kuning.

[3]Ginting, R. 2009.Penjadwalan Mesin. EdisiPertama. Yogyakarta : Graha Ilmu.

[4]Hardiyatmo, H.C. 2009. Pemeliharaan Jalan Raya; Perkerasan, Drainase, Longsoran.Cet. 2.Yogyakarta : Gadjah Mada University Press.

[5]Komatsu. 1983.Specification and Application Handbook.Ed. 15Jepang.

[6]Nabar, D. 1998. Peminahan Tanah Mekanis dan Alat Berat.Palembang :Universitas Sriwijaya.

[7]Rochmanhadi. 1989.Alat-alat Berat dan Penggunaannya.Jakarta : YBPPU.

[8]Rostiyanti, S.F. 2008.Alat Berat untuk Proyek Konstruksi.Ed. II.Cet. I.Jakarta: Rineka Cipta.

[9]Rosyidi. 2015.Rekaya Jalan Kereta Api. Yogyakarta: LP3M. 
[10]Rudenco, N. 2006.Mesin Pengangkat. Cet. 4.Jakarta : Erlangga.

[11]Zainuri, A.M. 2010.Mesin Pemindah Bahan.Jakarta : Andi Publisher. 